\title{
A urbanização moçambicana contemporânea: sua característica, sua dimensão e seu desafio' 1
}

\author{
The contemporary mozambican urbanization: its characteristics dimension and \\ challenges
}

\author{
Joaquim Miranda Maloa[a,b] (1)
}

[a] Universidade católica de Moçambique (UCM), Faculdade de Gestão de Recursos Florestais e Faunísticos, Lichinga, LX, Moçambique

[b] Instituto de Formação em Administração Pública e Autárquica de Lichinga (IFAPA), Lichinga, LX, Moçambique

Como citar: Maloa, J. M. (2019). A urbanização moçambicana contemporânea: sua característica, sua dimensão e seu desafio. urbe. Revista Brasileira de Gestão Urbana, 11, e20180101. https://doi.org/10.1590/2175-3369.011.e20180101

\section{Resumo}

$\mathrm{Na}$ perspectiva de uma geografia urbana, este artigo trata da urbanização moçambicana contemporânea. Objetiva-se, primeiro, apresentar algumas características dominantes dessa urbanização; em seguida, esboçar a sua dimensão; e, por último, expor os principais desafios que a urbanização contemporânea em questão tem para instituir, constituir e conservar o desenvolvimento urbano num em um país marcadamente pobre e subdesenvolvido. 0 trabalho de campo e a documentação consultada permitem inferir que a urbanização contemporânea se manifesta cada vez mais como extensiva. A marcha dessa extensividade é realizada pela valorização atual das áreas periféricas. A população mais pobre migra para locais bem distantes do centro. Concomitantemente, aumentam-se os problemas de mobilidade urbana e de falta de serviços e infraestruturas urbanas. Ressalta-se que as características mais dominantes são, nomeadamente, as seguintes: a dualidade urbana, a ruralidade no urbano, a informalidade e o crescimento demográfico urbano. Para que essa realidade seja modificada em Moçambique, é preciso ocorrer muitas transformações que serão realizadas ao longo do tempo e à medida que se vão criando as capacidades humanas, sociais, políticas, institucionais, tecnológicas e econômicas para a resolução dos problemas urbanos.

Palavras-chave: Urbanização moçambicana. Dualidade urbana. Ruralidade no urbano. Informalidade.

\section{Abstract}

In the perspective of urban geography, this article deals with the contemporary Mozambican urbanization. The objective is to first present some dominant characteristics of the Mozambican urbanization, then, to outline the dimension of that urbanization and, finally, to be liable to the major challenges that this contemporary urbanization has to establish, providing and maintaining urban development in a markedly poor and underdeveloped country. Fieldwork and documentation consulted

\footnotetext{
${ }^{1}$ Originalmente apresentado no dia 22 de outubro de 2015, no Instituto de Estudos Brasileiros (IEB) da Universidade de São Paulo (USP), no Café Acadêmico. A debatedora foi a professora Marina de Mello e Souza, e a organizadora do evento, a professora Vanderli Custódio.
}

JMM é sociólogo e geógrafo, pós-doutor, e-mail: joaquimmaloa@gmail.com 
allows inferring that contemporary urbanization is more and more extensive. The march of this extensivity is accomplished by the updated valorization of the peripheral areas. The poorest populations migrate to places far from the center. Concomitantly, it increases the problems of urban mobility, of the lack of urban services and infrastructures. Resulting repulsion of the countryside and the attraction of urban space, which frames the recent transformation of the economy. It brings out also that the most dominant features are the following: the urban duality, rurality in urban, informal and urban population growth.

Keywords: Mozambican urbanization. Urban duality. Rurality in urban. Informality.

\section{Introdução}

As informações contidas neste artigo valem-se de métodos e técnicas diversificados para a sua sustentação: reportagens jornalísticas, entrevistas com vários especialistas em urbanização moçambicana, pesquisas bibliográficas e observação direta em diversas cidades, com destaque para Maputo, Matola, Beira, Nampula, Tete e Lichinga ${ }^{2}$, onde foram entrevistados, durante cinco anos (20122017), diferentes especialistas (arquitetos, geógrafos, sociólogos, antropólogos, demógrafos e historiadores) que lidam com questões urbanas ${ }^{3}$, com o intuito de captar evidências que possam explicar as caraterísticas da urbanização do país. Moçambique situa-se na costa oriental da África Austral, no oceano Índico, e faz fronteira com seis países (Tanzânia, Malawi, Zâmbia, Zimbábue, África do Sul e Suazilândia). Tem uma faixa costeira de $2.700 \mathrm{~km}$ e uma área de $799.380 \mathrm{~km}^{2}$, organizado em 10 principais cidades 4 : Niassa (cidade de Lichinga), Cabo Delegado (Pemba) e Nampula (Nampula), ao norte; Zambézia (Quelimane), Tete (Tete), Manica (Chimoio) e Sofala (Beira), ao centro; Maputo (capital do país), Gaza (Xai-Xai) e Inhambane (Inhambane), ao sul, como mostra a Figura 1.

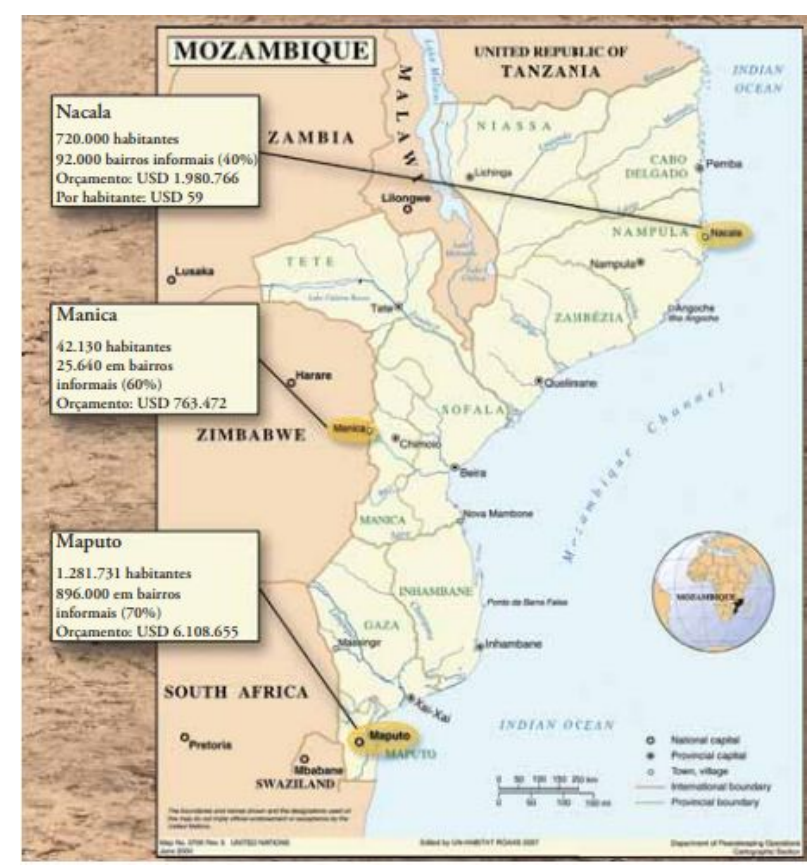

Figura 1 - Mapa de Moçambique com divisão administrativa de 10 províncias. Fonte: UN-HABITAT (2007).

\footnotetext{
${ }^{2}$ A escolha dessas cidades foi estabelecida de uma forma aleatória. Trata-se de cidades que o autor deste artigo recorre com frequência para questões de trabalho e de visita familiar.

3 Todas as entrevistas foram feitas dentro das instalações onde trabalhavam esses especialistas, em conversas previamente agendadas, com dia e horário, e gravadas.

${ }^{4}$ São capitais provinciais. Uma província pode equivaler à estrutura de um Estado no Brasil.
} 
A proporção da população urbana de Moçambique é estimada em 36\%. Três quartos dessa população é composta de residentes informais que sobrevivem da agricultura de subsistência ou do trabalho temporário. Os esforços governamentais reduziram a pobreza, entre 1997 e 2003, de 70\% para 54\%. A migração contínua desde 1975, ano da independência para as cidades, é o que ofusca o desenvolvimento nas zonas rurais. É imperioso dizer que as principais cidades e a maioria da população se encontram ao longo do litoral de Moçambique, com $2.470 \mathrm{~km}$ de extensão. Os serviços urbanos básicos estão fora do alcance da maioria dessa população. Os relatórios do Banco Mundial reportam que a taxa de cobertura de serviços básicos de coleta de resíduos sólidos atinge aproximadamente 30\% dos residentes. Apesar de não existirem dados exatos, acredita-se que seja correto assumir essa proporção.

Em 1990, o país adotou uma nova constituição que substituiu a de 1975, levando Moçambique a uma República Democrática, com a realização das primeiras eleições democráticas em 1994. Assim, a partir momento, de cinco em cinco anos, ocorrem, permanentemente, eleições presidenciais, legislativas e municipais (UN-HABITAT, 2007).

Este artigo trata da urbanização moçambicana contemporânea. Para tanto, a pesquisa identificou três grandes objetivos: 1) apresentar algumas características dominantes da urbanização moçambicana; 2) esboçar a dimensão ${ }^{5}$ dessa urbanização; 3) expor os principais desafios a serem enfrentados na urbanização contemporânea.

A urbanização contemporânea deve ser aqui entendida como o processo de formação do espaço urbano do nosso tempo, mas o nosso tempo é vago. Dá-se como ponto de partida, principalmente, a década de 1990, que foi decisiva na história de Moçambique, profundamente influenciada pela introdução da economia de mercado (1990), pelo fim da guerra civil (1992) e pela realização das primeiras eleições gerais (1994).

Em Moçambique, a área urbana é formada por 23 cidades e 68 vilas. Dentro desse espaço urbano, surgiram mudanças significativas na urbanização moçambicana, que acabaram alterando profundamente a paisagem urbana, com aparecimento, de um lado, de novas configurações urbanas (condomínios e edifícios luxuosos de dois a três pisos) e, do outro lado, de novos bairros, cada vez mais distantes dos centros urbanos, com ausência de serviços públicos, asfaltamento, iluminação, transporte, educação e saúde.

\section{As caraterísticas da urbanização moçambicana}

Dada a falta de espaço no contexto deste artigo, esta análise não poderá fazer justiça a todas as caraterísticas do processo da urbanização moçambicana. As características mais predominantes nesse processo são, nomeadamente: a dualidade urbana, a ruralidade no urbano, a informalidade e o crescimento demográfico.

\section{A urbanização dual}

A urbanização dual como uma das caraterísticas da urbanização moçambicana contemporânea, aqui tratada a partir da década de 1990, resultou de um processo longínquo de segregação socioespacial, caracterizada pela natureza colonial que o país passou por longos séculos. Como mostrou Fanon (2005) na sua obra "Os condenados da terra", o colonialismo perpetuava valores segregacionistas e racistas, os quais estruturaram as cidades moçambicanas em dois compartimentos: de um lado, bairros configurados em plantas ortogonais, com edifícios verticais, redes de serviços, comércio, saneamento básico, abastecimento de energia elétrica, água potável, telecomunicações etc.; do outro lado, bairros estruturados em habitações horizontais, precárias em infraestrutura e serviços urbanos. Para efeito de ilustração, apresenta-se a Figura 2.

\footnotetext{
50 termo "dimensão" deve ser aqui entendido como sinônimo de tamanho, extensão e distância.
} 


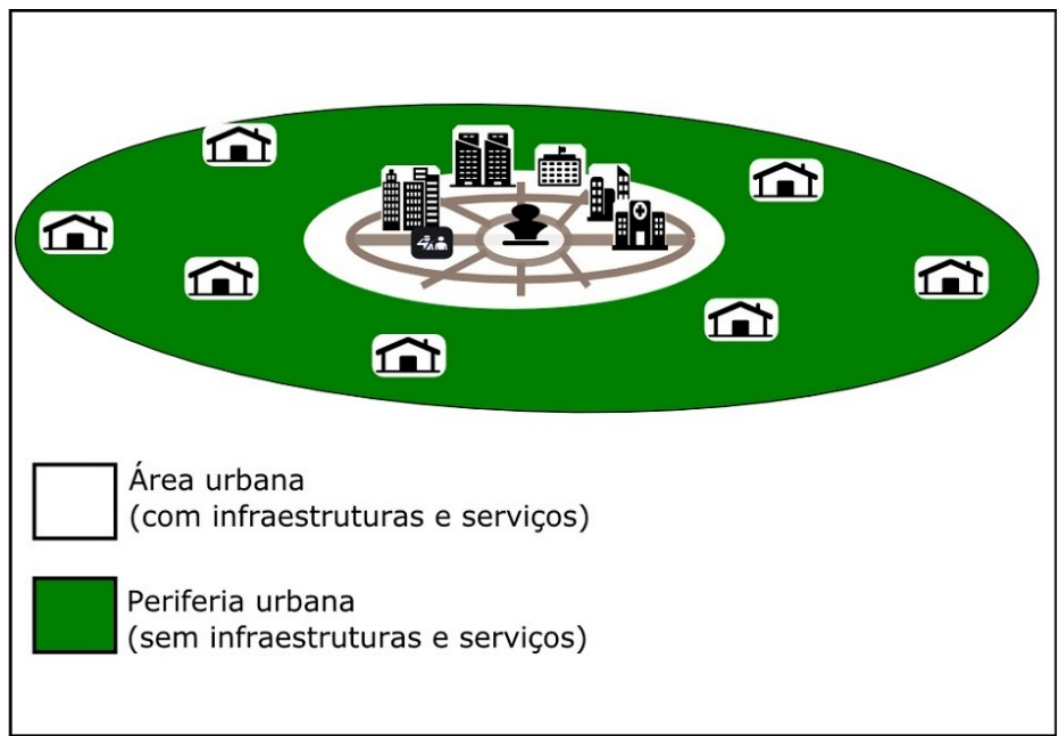

Figura 2 - Modelo colonial de segregação socioespacial. Fonte: Maloa (2016).

É de sublinhar que, no campo da geografia urbana moçambicana, essa urbanização colonial dual ficou conhecida como o binômio "cidade do cimento" versus "cidade do caniço"6, ou seja, coexistiam, no mesmo espaço urbano, duas "cidades" vivenciadas de forma diferente por dois tipos de moradores: os "colonos" e os "colonizados" (Mendes, 1979, Mendes \& Fernandes, 2012; Araújo, 1999, 2003; Raposo \& Salvador, 2007; Oppenheimer \& Raposo, 2007; Morais, 2001; Fonte, 2007).

Para estabelecer a data da intensificação da dualidade urbana colonial, pode-se localizar as décadas de 1930-1970, dominadas pelo período do "colonialismo tardio" (Castelo et al., 2012). Nesse período, ocorreu uma série de acontecimentos que permitiram uma segregação urbana sistemática, por exemplo: barreiras raciais na ocupação e no uso do solo urbano; êxodo rural, provocado pela intensificação do Xibalo ou Chibalo7; política colonial de integração forçada dos colonizados no trabalho assalariado, como a obrigatoriedade de os colonizados rurais pagarem tributos, especialmente com a reorganização dos impostos aplicáveis à população negra de 1942 (Circular 818/D7 (Moçambique, 1942), que determinava que os tributos seriam definidos pela capitação de rendimento individual; já as mulheres e os homens inválidos, a partir dos 18 anos, pagariam imposto reduzido (Hedges \& Rocha, 1999)8; e aumento da população colona, articulado pelos Planos de Fomentos de 1953-1958, 1959-1964 e 1968-19739', como mostra a Figura 3.

\footnotetext{
6 Em Moçambique, chama-se de "caniço" as plantas do gênero Typha, muito utilizadas na construção de casas (Viana, 2010). Utilizava-se o nome de "cidade de caniço" por causa do material mais usado na cobertura das casas (Araújo, 2003).

7 Trabalho forçado no campo.

${ }^{8}$ Nesse processo de estruturação da urbanização colonial dual, a cidade de Lourenço Marques, atual Maputo, foi a que recebeu o maior número de imigrantes rurais a procura de trabalho assalariado, principalmente de construção civil, limpeza da cidade, empregados domésticos, estivadores dos Portos e Caminhos de Ferro de Moçambique, especialmente vindos da região sul do país, como os Xitswas, Xirongas, Gitongas, Cichopis e Xichanganas (Silva, 2011), que acabaram fixando suas residências nas periferias, como bem documenta Mahumane (2007), ao historicizar o surgimento, na década de 1940, do bairro periférico Chinhambanine - o nome trata da população proveniente das áreas rurais da província do Inhambane. Atualmente, o bairro é conhecido por Luis Cabral, em homenagem ao segundo presidente de Cabo Verde

${ }^{9}$ Para saber da política de migração do Estado novo para as colônias de Moçambique, ver Castelo (2007) e Castelo et al. (2012).
} 


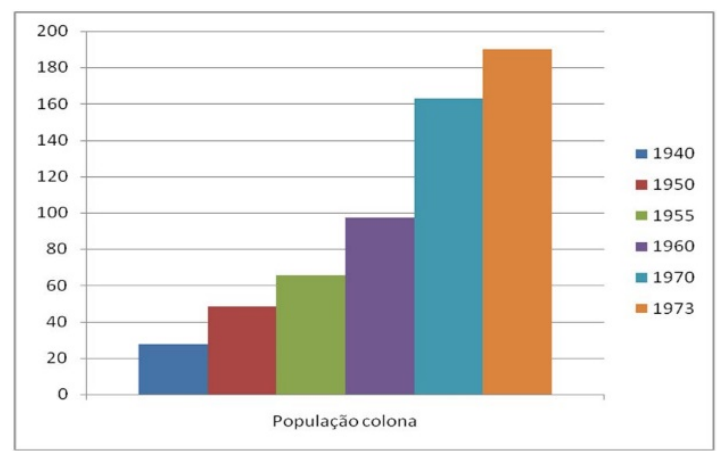

\begin{tabular}{|l|l|l|l|l|l|r|}
\hline Anos & 1940 & $\mathbf{1 9 5 0}$ & $\mathbf{1 9 5 5}$ & $\mathbf{1 9 6 0}$ & $\mathbf{1 9 7 0}$ & $\mathbf{1 9 7 3}$ \\
\hline Pop. Colona & 27.438 & 48.213 & 65.798 & 97.245 & 162.967 & 190.000 \\
\hline
\end{tabular}

Figura 3 - Estimativa do crescimento da população colona em Moçambique. Fonte: Castelo (2007).

O crescimento da população colonial veio consolidar a estrutura do centro urbano ("cidade do cimento") como o espaço do colono, e o seu entorno ("cidade do caniço") como o espaço do colonizado (Mendes \& Fernandes, 2012; Maloa, 2016). Com o fim do colonialismo português em 1974 e com a independência nacional em 1975, a urbanização moçambicana herdou os problemas estruturais da urbanização dual, ampliados em razão de alguns fatores. O primeiro ocorreu quando houve a "reclassificação urbana" de 1986, por meio de "decreto presidencial" que aumentou a divisão administrativa urbana do país, com a integração de novos espaços urbanos periféricos. Como escreveu Araújo (2003), milhares de famílias adormeceram como rurais e acordaram, no dia seguinte, como urbanas, sem que tivessem sido processadas quaisquer alterações de organização espacial, econômica, social ou cultural. A legislação permitiu retirar espaços rurais - terras agrícolas que estavam sob administração dos Distritos ${ }^{10}$ - em favor dos espaços urbanos. A "reclassificação urbana" de 1986 não trouxe nenhum benefício para o desenvolvimento dos espaços urbanos, segundo Araújo (2003). Na verdade, permitiu a expansão das periferias sem infraestruturas e serviços urbanos, amontoando gente em condições desumanas ou indigentes. Como mostra a Figura 4, é possível os traços vermelhos que separam o centro, com edifícios verticais, da periferia, extensa e com edifícios horizontais.

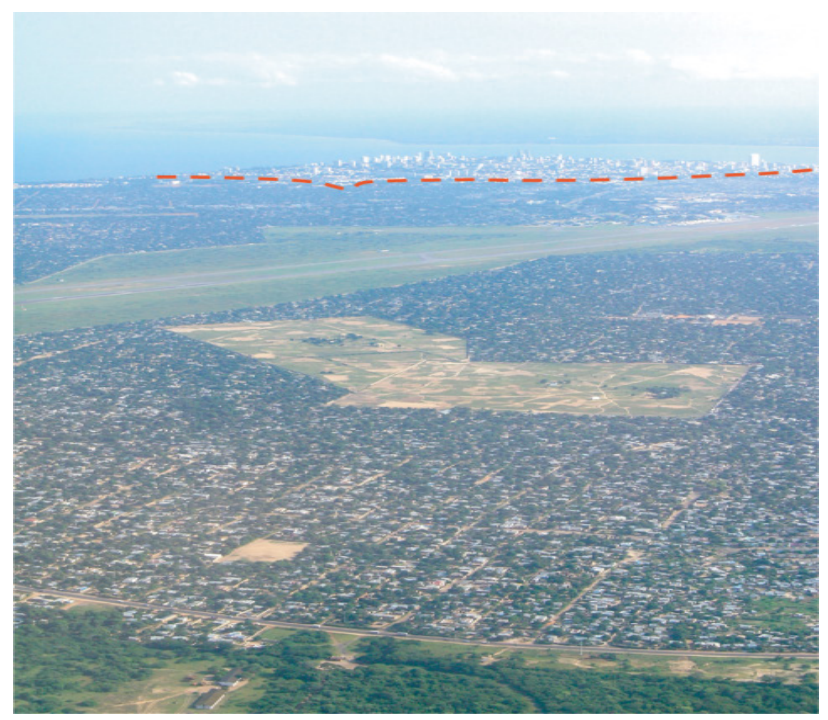

Figura 4 - Foto aérea da cidade de Maputo. Fonte: Folio (2007).

\footnotetext{
${ }^{10}$ A organização territorial da República de Moçambique organiza-se em: províncias, com capital cidade; distritos, com sede chamada de vila ou cidade; postos administrativos; localidades; e povoações.
} 
O segundo ocorreu com a guerra civil de dezesseis anos (1976-1992), que atingiu por igual todo o território nacional, com grande intensidade para as províncias do centro do país (Sofala, Zambézia, Tete e Manica), acompanhado por desastres naturais (calamidades naturais, cheias e secas) na década de 1980. As cidades moçambicanas se tornaram um lugar seguro de refúgios ${ }^{11}$, que acabou influenciando a "implosão urbana"12, por causa da ocupação do centro e das áreas de não edificação ou áreas de proteção13, como: espaços "vagos" ou "vazios" para as futuras instalações de edifícios públicos, valas de drenagens (córregos), encostas marítimas, dunas etc. Já "explosão urbana14" se deu em razão da ocupação das periferias com surgimento de novos bairros de ocupação espontânea e desordenada. Como escreveu Raposo (2010, p. 185), as periferias:

Continuam a crescer mais depressa que os centros urbanizados, densificando-se e expandindo-se, e, nas últimas duas décadas, têm sido palco de grande transformação, a qual é sobretudo o resultado da acção dos seus habitantes que gradualmente, com os seus mais ou menos parcos recursos, investem na melhoria do seu espaço habitacional, face à insuficiência das intervenções públicas e ao carácter pontual da acção dos novos actores desta cena periurbana, ONGs, congregações religiosas e, mais recentemente, organizações comunitárias de base.

O terceiro fator da ampliação da "dualidade urbana" ocorreu com o fim da guerra civil em 1992 e a introdução da economia de mercado 1994. Observou-se um processo intensivo de êxodo rural que ampliou também os espaços urbanos periféricos, influenciado pelas forças de atração e sedução do mundo urbano e das oportunidades de acesso a novos bens de consumo (Raposo, 2010).

Por fim, o quarto fator ocorreu com o aparecimento de um fervoroso mercado "formal" $e$ "informal" de terra na periferia, sobretudo nos anos 2000, provocado pela falta de espaço no centro e pela alta do preço do aluguel (Jenkis, 2001). Com esses mercados, as periferias estão ganhando novas dinâmicas, com habitações construídas de materiais híbridos (industrializados e naturais), como cimento, zinco argila, estaca, diversos tipos de tronco, palhas, telhas etc., moradias de cimento, blocos de argila secos ao sol ou ao forno, cobertas com zinco. Assim, mudou-se a paisagem da periferia, que, no período colonial até no início dos anos 2000, era chamado de "cidade do caniço". Como diz Mendes \& Fernandes (2012), essa mudança não é resultado de uma evolução estética subjetiva, mas antes por razões de ordem prática, pois os materiais de construção convencionais estão cada vez mais disponíveis e acessíveis ${ }^{15}$. Essas metamorfoses, na verdade, não estão mudando a estrutura dual da urbanização moçambicana ${ }^{16}$. Como aponta Raposo (2010, p. 185), aumenta-se a dualidade "[...] entre as áreas centrais requalificadas e as imensas periferias com insuficientes e deficientes infraestruturas, transportes e equipamentos urbanos". Essa percepção foi também corroborada por vários especialistas:

Com certeza a dualidade urbana aumentou nas cidades moçambicanas [...] na década de 80 era assim. O crescimento da periferia não tinha um regime muito parecido com o que temos hoje. Hoje, as pessoas que vêm à cidade vão viver nas periferias, mas não são oferecidos serviços básicos, isso em quase todas as cidades por onde passei [...] (ARQUITETO, entrevistado, Maputo, 22 out. 2014).

\footnotetext{
${ }^{11}$ Sobre a cidade como refúgio, ver Araújo (2003).

12 Um bom exemplo da interpretação do termo "implosão urbana" nas cidades moçambicanas pode ser encontrado em Araújo (2003). Para o autor, a "implosão urbana" significa que uma parte considerável do crescimento urbano não tem sido feito à custa do espaço periférico, mas tem sido o espaço periférico que avança em direção ao espaço central, conferindo a este características marcantes de "ruralização" e "suburbanização".

${ }^{13} \mathrm{Um}$ exemplo significativo de ocupação de espaços vazios no centro foi um conjunto (já removido) de casas precárias que existiam nas barreiras no vale do Infulene, em Maputo, e na Praia Nova, em Beira.

14 Termo retirado de Raposo (2010, p. 2), que afirma: “[...] a explosão urbana das últimas décadas, nos países em desenvolvimento e especificamente em África, deriva do persistente e elevado crescimento natural - resultante da diminuição da taxa de mortalidade e da permanência de altas taxas de fecundidade e natalidade, típica de países em desenvolvimento e de contextos de pobreza".

${ }^{15}$ Atualmente, as habitações de caniço estão sendo substituídas por cimento. Marchand (1995), na década de 1990, Baia (2009), Carrilho \& Lage (2009), Viana (2010), Costa (2011), nos anos 2000, e Maloa (2016) observaram que, em alguns bairros periféricos da cidade de Maputo, Beira, Tete, Chimoio e Lichinga, floresciam construções de cimento segundo as possibilidades dos proprietários, apesar de muitas habitações serem ainda de "caniço".

${ }^{16}$ Os problemas de infraestruturas e serviços urbanos persistem.
} 
[...] A dualidade urbana cresceu em relação a 30 anos atrás, em alguns sentidos, pois aí entra a falta de direitos ao transporte, à água potável, que traz problemas de saúde pública [...], por exemplo, as cóleras, que, no tempo chuvoso, têm atingido as nossas cidades [...] (GEÓGRAFO, entrevistado, Maputo, Beira, 8 maio 2017).

[...] na verdade, a dualidade em Moçambique mudou completamente. Há poucos anos atrás, você ainda não via essas áreas verdes de Matola, Zona Verde, Ndlavela, Infulene, Khongolote, Intaca, Muhalaze, Mali, Mukatine, Ngolhoza Infulene, Unidade A, Trevo, Patrice Lumumba, Bunhiça, Tsalala, km-15, Mathlemele, Cobe, Matola Gare, Singathela, Matola F, Matola G, Matola H, Matola J, Fomento, Mussumbuluco, Mahlampswene e Sikwama, ocupados como hoje, com muita pobreza [...]. (HISTORIADOR, entrevistado, Beira, 10 maio 2014).

Um estudo realizado por Andreatta \& Magalhaes (2011, p. 21), intitulado "Relatório sobre as condições do planejamento urbano, habitação e infraestruturas em Maputo Moçambique", observou essa diferenciação socio espacial, ao apontar que se constata "uma dicotomia entre planos urbanos, que são gerados por demanda de um establishment de poder culto, formado na Europa, e a transmissão prática, oral, baseada em manuais de construção simples que incidiram na técnica de construção da cidade". A cidade de caniço é aquela que, embora consolidada pelas décadas, ainda apresenta aspecto geral de moradia mais precária. Já a cidade de cimento, a própria denominação dos moçambicanos não deixa dúvidas, refere-se àquela cidade que "foi sendo construída pela urbanização portuguesa e que hoje corresponde à malha urbanizada, formal e ordenada" e concentra a grande maioria das atividades econômicas, culturais, desportivas, administrativas e empresariais.

\section{Ruralidade no urbano}

A segunda característica fundamental da urbanização moçambicana é a ruralidade no urbano. Nessa relação entre o urbano e o rural, pesam os aspectos institucionais de mudança entre o que é considerado urbano e rural, que nem sempre refletem mudanças substantivas no modo de vida da população urbana. Trata-se de uma característica quase geral nos países africanos (Moriconi-Ebrard et al., 2015), herdada também do período colonial e muito visível atualmente nas periferias, nas quais prevalecem a população de baixa renda, principalmente aqueles que migram dos espaços rurais para os espaços urbanos a procura de sobrevivência, como forma de lidar com a difícil vida urbana, e acabam adaptando atitudes, hábitos e comportamentos rurais, dando origem ao fenômeno chamado de "ruralidade no urbano" (Baia, 2004, 2009) ou "ruralização do urbano" (Araújo, 2001, 2003). Apesar de mostrar-se como transitória, ainda persiste essa característica em quase todas as cidades moçambicanas. Toma-se como exemplo o bairro periférico da cidade de Lichinga ao norte do país (Figura 5). 


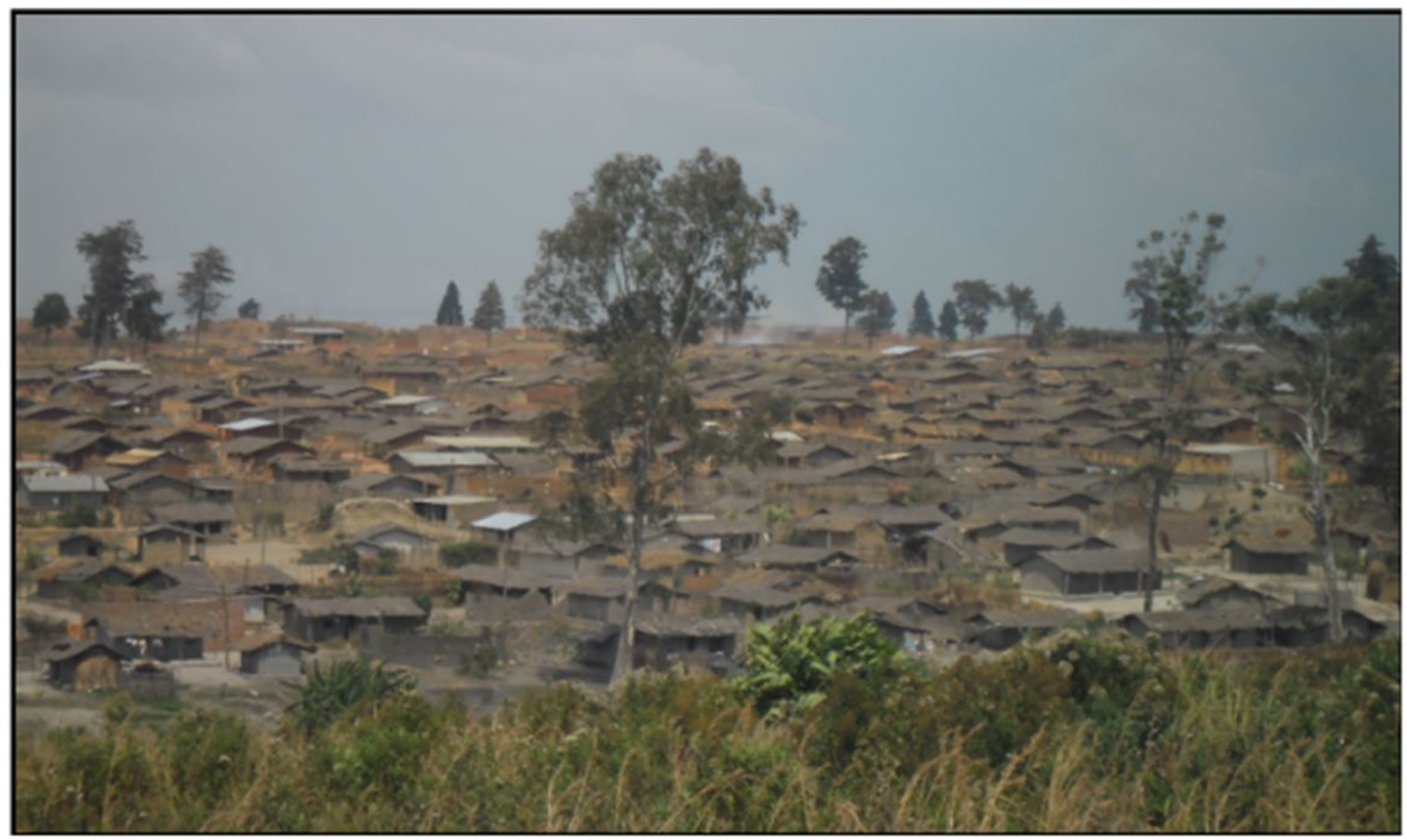

Figura 5 - Bairro periférico da cidade de Lichinga. Fonte: autor (2013).

Segundo Araújo (1999, 2001), o termo "rural no urbano" é muito polêmico, porque leva a questionar a aplicação linear da delimitação clássica das designações urbano e rural. A questão fundamental desse processo está no fato de a urbanização moçambicana ainda se encontrar pouco desenvolvida. Atualmente, é impossível separar, na urbanização moçambicana, o hibridismo (o rural e o urbano). Eles encontram-se mesclados, configurando linguagem, práticas, formas urbanas e percepções do uso e organização do espaço urbano. Por exemplo, grande parte da população urbana mora na periferia, em habitações de caniço, Mathapuita ${ }^{17}$, palhotas ou palhoças tipicamente rurais, incorporando outros tipos de materiais precários. Como aponta Mendes \& Fernandes (2012), nas periferias a população urbana não tem acesso à água canalizada, consumindo águas dos poços ou furos de água, e eletricidade, recorrendo ao combustível lenhoso como fonte de energia. Como mostra a entrevista:

[...] detectei que a maioria da população da periferia vive em palhotas tipicamente rurais e era formada de camponeses, o que significa que os agregados familiares vivem da agricultura familiar [...] e muitas casas não têm acesso à água canalizada [...] são indicadores importantes da urbanidade (SOCIÓLOGO, entrevistado, Maputo, 12 jun. 2014).

Já dizia o professor catedrático Manuel Araújo (2001), do Departamento de Geografia da Universidade Eduardo Mondlane, em Maputo, Moçambique, que a ruralidade no urbano possui características dos bairros periféricos das cidades moçambicanas. Os traços da ruralidade são construídos por fraca capacidade do poder público de transformar esses espaços em urbanizáveis, mas também dos residentes em transformar esses territórios, uma vez que são constituídos por camponeses sem poder aquisitivo para ter uma habitação condigna, vivendo em palhotas, sem eletricidade e água potável, e recorrendo a sistemas alternativos utilizados nos espaços rurais, mantendo, assim, características do rural no urbano.

\footnotetext{
${ }^{17}$ Literalmente, significa "farrapos de gentes" em língua Emakhuwa, falada ao norte de Moçambique (Serra, 2003).
} 


\section{Informalidade}

A terceira característica da urbanização moçambicana contemporânea é a informalidade no que diz respeito ao acesso à terra urbana. Em Moçambique, a terra pertence ao Estado. A Lei de Terra, em vigor desde 1997, concede a indivíduos o direito à terra com base em ocupação histórica, aceitando as testemunhas orais para decisão. Incorporando a lei tradicional, esse processo foi amplamente respeitado como reforma agrária. Apesar de quase 14 anos, a lei não demonstrou eficácia na concessão de direitos de residência permanente de seus ocupantes. Interesses contraditórios por promotores de terra, falta de procedimentos adequados de planejamento urbano, pesquisas, processos burocráticos, taxas altas e corrupção, tudo contribui para que os assentamentos permaneçam informais (UN-HABITAT, 2007), motivado pelo processo burocrático de aquisição de terras urbanas ${ }^{18}$.

A aquisição de terras urbanas ou lote ${ }^{19}$ ocorre de duas formas. A primeira forma ocorre quando o morador está fixado no lote há muito tempo (pelo menos há cinco anos). 0 lote deve ser reconhecido pelo secretário do bairro, e, depois, o requerente submete a solicitação ao município. Na sequência, este avalia se os documentos submetidos estão de acordo com as exigências. Por último, o município cobra uma taxa para que o requerente tenha o Direito de Uso e Aproveitamento da Terra (DUAT) ${ }^{20}$. A segunda forma de aquisição de terras urbanas ocorre quando os municípios lançam os editais da existência de lotes urbanizáveis. Os munícipes redigem uma carta solicitando as manifestações do aproveitamento da terra urbana e indicando o tipo de edifício que pretendem erguer, anexado à planta. A ocupação de um lote depende da taxa de construção e do tipo de projeto sugerido pelos municípios ${ }^{21}$. Isso, por vezes, torna caro o acesso à terra urbana para a população, principalmente de baixa renda. Assim, ocorrem a falta de registro e de autorização formal do DUAT e a venda informal de lotes urbanos, uma vez que a terra urbana é propriedade do Estado e é invendável ou, de qualquer outro modo, transferida ou hipotecada. Sobre essa realidade, um dos entrevistados apontou:

A crescente taxa de urbanização tem pressionado a procura de habitação nas áreas periféricas das cidades, o que acaba por estimular uma ocupação informal de terra, que, muitas vezes, entra em conflito com os municípios na aquisição do DUAT, entre aquele que ocupou anteriormente e o interesse econômico desejado [...]. Outro fator que contribui para essa enorme procura de terra urbana são ainda os emergentes mercados de terras. Presume-se que alguns negócios de aquisição de terra possam a ser realizados tendo como expectativa que a longo prazo esta venha a valorizar ainda mais [...]. (DEMÓGRAFO, entrevistado, Maputo, 20 jun. 2017).

A crescente procura de terra urbana em Moçambique abriu uma brecha para o surgimento de um mercado informal de terra facilitado pelas inúmeras falhas em todo o processo de atribuição do Direito de Uso e Aproveitamento da Terra, beneficiando a população que possui poder aquisitivo, em detrimento dos que não possuem, uma vez que a pobreza urbana é alta e grande parte da população em idade ativa está desempregada. Além disso, o Estado mostra-se limitado para fortalecer as instituições que trabalham com questões de terra, sem contar a fraqueza institucional dos governos locais, a corrupção de autoridades e líderes comunitários e a falta de recursos financeiros para obtenção dos benefícios dos processos formais da posse de terra. 0 maior agravante nesse fenômeno é a vulnerabilidade resultante das inúmeras carências características da pobreza que afeta grande parte da população urbana (Mosca, 2009).

\footnotetext{
${ }^{18}$ Para discussão sobre esse assunto, ver Jenkis (2001).

${ }^{19}$ Em Moçambique, utiliza-se o termo "talhão" em vez do "lote".

${ }^{20}$ Segundo Desenvolvimento Municipal em Moçambique (ANAMM, 2009, p. 49), “O Direito de Uso e Aproveitamento da Terra [...], o DUAT, é concedido a pessoas naturais ou jurídicas com base nos fins sociais ou econômicos que se propõem [...]”, introduzido pela Lei de Terras (Decreto-lei no 19/1997).

${ }^{21}$ Por vezes, são os municípios que determinam que tipo de edificação deve ser levado a cabo na área em que o requerente submete o pedido do DUAT.
} 


\section{Crescimento demográfico}

A quarta e última característica da urbanização moçambicana contemporânea é o rápido crescimento demográfico no espaço urbano influenciado pelo êxodo rural e pelas altas taxas de natalidade (Ibraimo, 1994; Mapengo, 2011; Cau \& Arnaldo, 2015; Carvalho, 2015). Só para ter uma ideia, a população urbana, entre as décadas de 1980 e 1990, cresceu 15\%, apresentando, em 1997, um total de 29,2\% (Araújo, 2001). Isso quer dizer que a população urbana duplicou. 0 Programa de Desenvolvimento das Nações Unidas (UNDP, 2007) calculava que, em 2007, a taxa de crescimento demográfico seria de 34,5\% para a população urbana (Figura 6) e estima que, em 2025, a taxa será de $50 \%$.

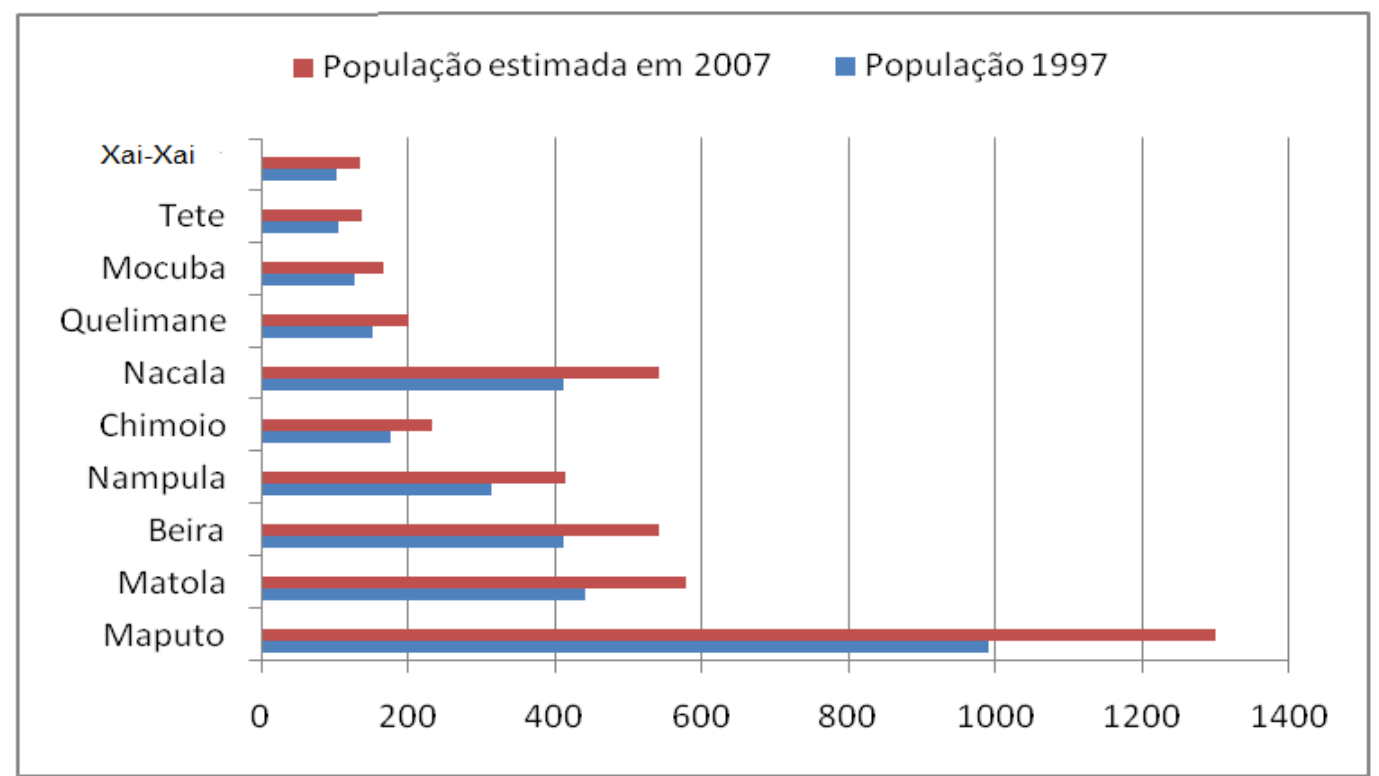

Figura 6 - Estimativa do crescimento populacional nas maiores cidades moçambicanas. Fonte: Instituto Nacional de Estatística (INE, 2004). Adaptada pelo autor (2016).

As estatísticas urbanas da África subsaariana mostram que esse fenômeno é geral e não está apenas circunscrito a Moçambique (Figura 7). Como aponta Raposo (2010, p. 1), "[...] recente crescimento acelerado das grandes cidades africanas é muito mais rápido que o vivido nos países ocidentais nas primeiras décadas da Revolução Industrial".

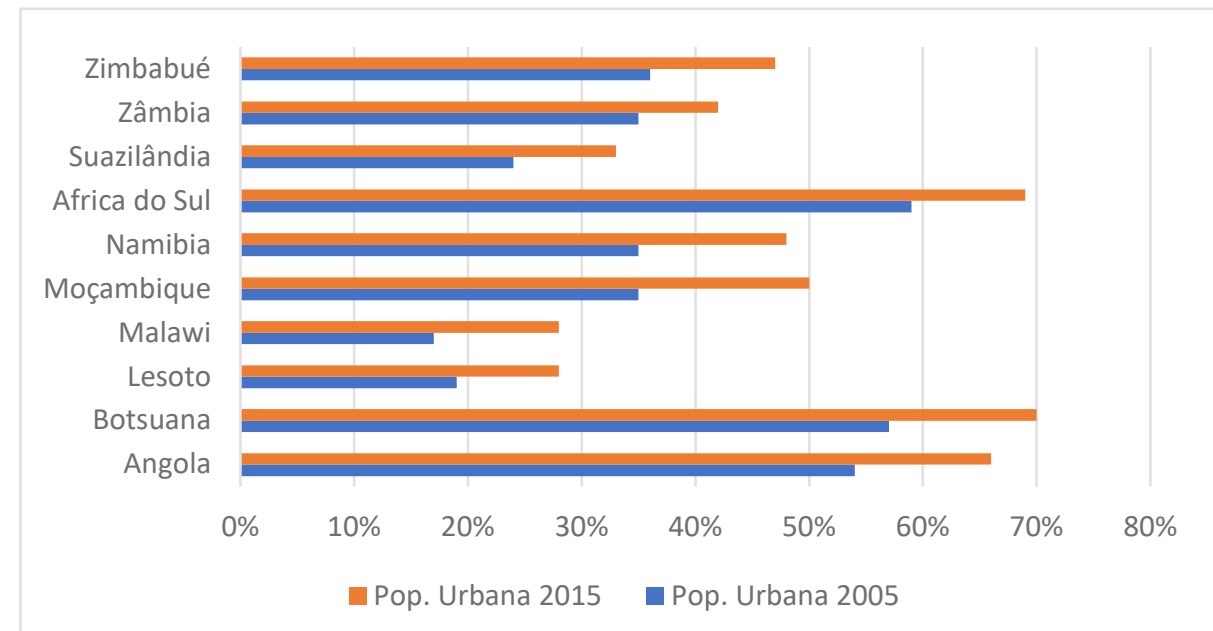

Figura 7 - Crescimento populacional na África Austral. Fonte: United Nations (UN-HABITAT, 2007). 
Na África subsaariana, o crescimento populacional urbano não tem sido acompanhado pelo processo de implementação e distribuição equitativa de serviços e infraestruturas, "[...] resultando no agravamento da pobreza urbana e na degradação das condições do meio urbano [...]" (Jenkis, 2001, p. 2).

\section{A dimensão da urbanização moçambicana}

É sem dúvida a partir da década de 1990 que se teve início o crescimento das periferias urbanas em Moçambique, "[...] sem que isso tivesse sido acompanhado pelo correspondente crescimento de infraestruturas e serviços urbanos" (Araújo, 2003, p. 170). Como aponta Raposo (2010, p. 1), é dramático ver as imagens das extensas "periferias das cidades [...] com habitações precárias, densamente ocupadas, sem infraestruturas, nem serviços [...]". Há nesse processo uma "urbanização extensiva" (Viana, 2012), provocada pelo papel do mercado de terra, que acaba configurando esses espaços como o mais barato e atraindo mais residências em condições precárias. Conforme Andreatta \& Magalhaes (2011), as vias de acesso à "cidade de cimento" parecem ter sido implantadas atravessando os bairros e, de nenhum modo, tiveram algum componente de articulação com eles, gerando um efeito barreira na sua execução. 0 equilíbrio funcional da cidade é precário. No aspecto de mobilidade e acessibilidade, a "estrutura viária exígua e a falta de acessibilidade e transportes oferecidos condenam a população periférica". Uma representação da dimensão da urbanização moçambicana, provocada pelo crescimento extensivo da periferia, encontra-se na Figura 8.

A dimensão da urbanização moçambicana cresce com fraca assistência de instrumentos de planejamento do uso e da ocupação do solo, sua execução e seu controle. Como resultado, a maior parte da população urbana passou a residir em áreas sem acessos adequados à mobilidade urbana (Carrilho \& Lage, 2009) e sem segurança da posse da terra (Forjaz et al., 2006).

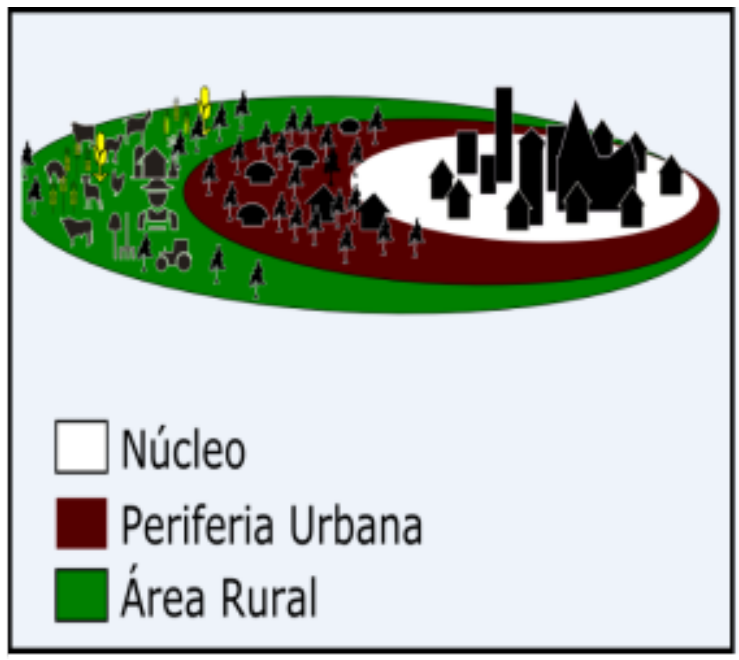

Figura 8 - Padrão contemporâneo do crescimento urbano. Fonte: Maloa (2016).

Atualmente, as periferias urbanas estão muito próximas de romper com os limites administrativos dos distritos vizinhos, pois há muita demanda por áreas periféricas por parte dos residentes privilegiados do centro urbano, uma vez que nelas pretendem construir a sua segunda ou terceira residência (Figura 9). Nesse processo, o elo mais fraco é a retirada da família de baixa renda (Araújo, 2003). 


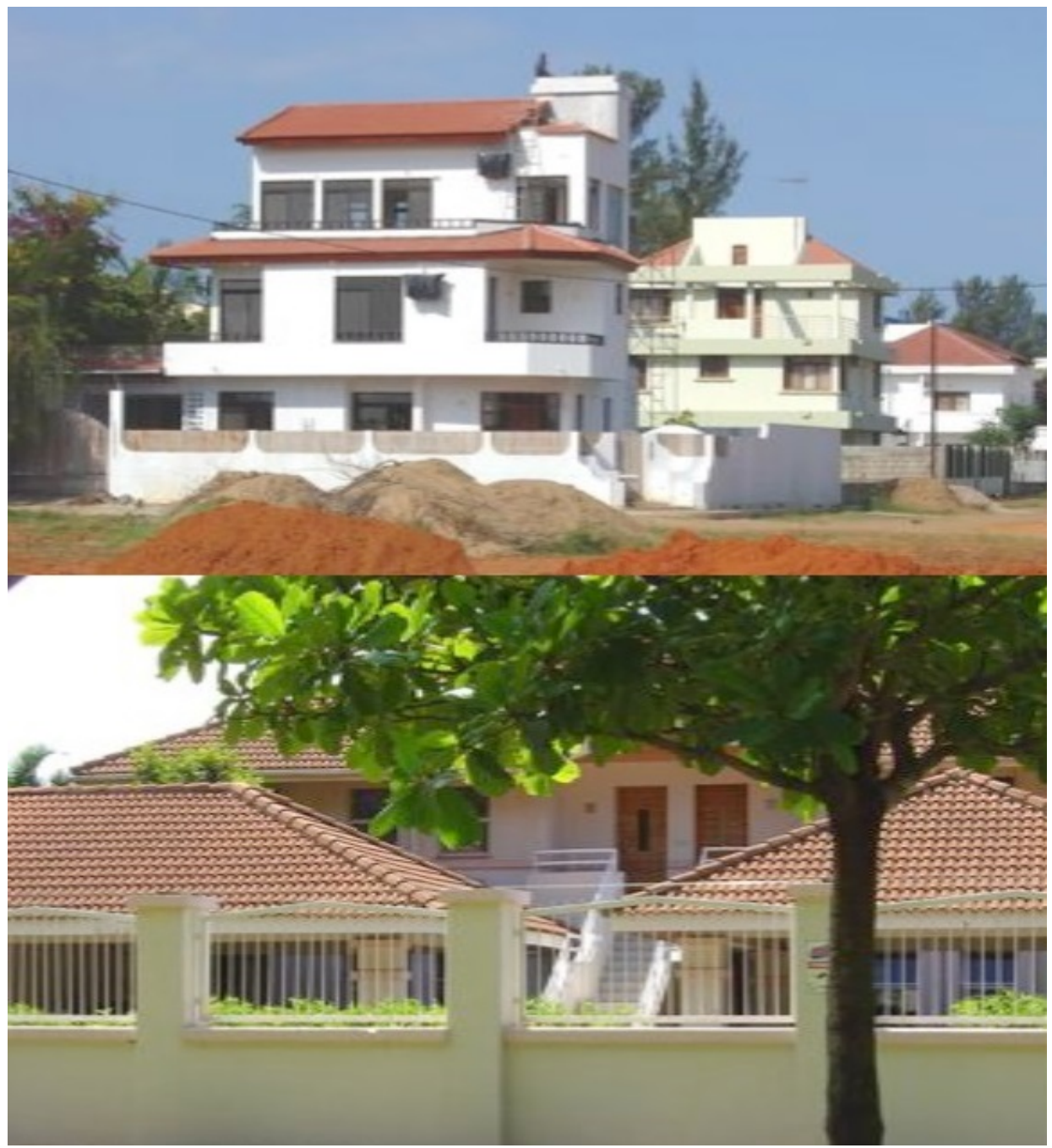

Figura 9 - Vista parcial de habitação de alto padrão na periferia da cidade de Maputo. Fonte: Folio (2007).

A observação direta da estrutura e da organização urbana realizada no trabalho de campo mostrou uma urbanização extensiva e de pobreza em Maputo, Matola, Beira, Nampula, Tete e Lichinga, seguindo o modelo de urbanização que o professor catedrático Jochen Oppenheimer e a professora Isabel Raposo (2007), ambos da Universidade Técnica de Lisboa, chamam de "macrocefalia", ou seja, o crescimento desmensurado desses espaços, causado por uma urbanização acelerada que polariza espaços.

\section{Considerações finais: desafios da urbanização moçambicana}

Dadas as principais características da urbanização moçambicana contemporânea indicadas, importa ressaltar que esta análise não pode fazer justiça a todos os desafios. Reconhece-se que os desafios são enormes. Trata-se de mudanças na política urbana e na base institucional existentes, por exemplo: Programa de Desenvolvimento do Município de Maputo (PROMAPUTO); Programa de Reabilitação Urbana (PRU); Programa de Habitação (PROHABITA) (1987); Plano de Estrutura da Cidade de Maputo (1985); Política e Estratégia de Habitação (PEH) (2011); Plano de Implementação do Plano e Estratégia de Descentralização 2016-2019 (2016); Estratégia de Promoção de Desenvolvimento Autárquico e Urbano (2017), entre outros, que possam alterar o padrão da urbanização ${ }^{22}$; reconhecimento do papel do financiamento da urbanização no que tange à implantação de infraestrutura e serviços urbanos;

\footnotetext{
${ }^{22} \mathrm{O}$ padrão deve ser entendido como modelo.
} 
fortalecimento das relações intersetoriais entre as instituições que trabalham com questões urbanas; e mudança do ponto de partida das estratégias de desenvolvimento urbano.

Expostos esses pontos, cabe elaborar algumas questões: como é que essas transformações podem ser realizadas? Na verdade, a superação dos desafios da urbanização do país depende de vários agentes de produção do espaço urbano: os promotores imobiliários (empreteiros e empresas imobiliárias), que ganham expressividade na restruturação ou na requalificação urbana; os grupos sociais urbanos pobres, que ocupam grande parte dos espaços e acabam caracterizando a dimensão da urbanização e polarizando, cada vez mais, o centro como um lugar de grandes investimentos e a periferia como o lugar de carência; e o Estado, que tem um papel importante de incentivar as instituições, os mercados e os agentes econômicos.

Como a administração pública lida com esse fenômeno? Sabe-se que o Estado moçambicano enfrenta dois grandes problemas estruturais para enfrentar o desenvolvimento urbano: não dispõe de capital nem de instituições perfeitas. No sentido de apoiar o esforço moçambicano de estruturar melhor o desenvolvimento urbano, existem, portanto, várias possibilidades de intervenções urbanísticas. Cada caso se converte em um exemplo particular, com conotações próprias. Não obstante, um dos grandes desafios começa pela criação de uma Política Nacional de Desenvolvimento Urbano, ou seja, uma Política Nacional de Urbanização, capaz de propor políticas de incentivos fiscais, tributários e financeiros, de modo a privilegiar os investimentos e a mobilizar recursos e despesas públicas para financiar a urbanização moçambicana.

A implementação dessa política não será uma tarefa fácil, uma vez que o orçamento do Estado depende dos doadores estrangeiros, principalmente da União Europeia (EU). A dependência não pode ser vista como limite, mas como um desafio para procurar outras alternativas de financiamento, que podem ser levados a cabo por meio de coletas de impostos autárquicos, inclusão de linhas orçamentais no orçamento geral do Estado ${ }^{23}$ e de parceria público-privada (PPP) ${ }^{24}$. Como mostra Nguenha (2009), os países em desenvolvimento têm usado esse tipo de modelo de financiamento de urbanização, sem aumentar o seu endividamento nem a carga fiscal, ao mesmo tempo que transferem parte do risco e dos custos de investimento para ambos 25 .

Este artigo se encerra apontando que existe em Moçambique um debate sobre urbanização contemporânea feito por arquitetos, geógrafos, sociólogos, antropólogos, demógrafos e historiadores, entre outros, que ainda está aberto. Este texto é uma contribuição para o que está acontecendo no país, em prol de um desenvolvimento urbano.

\section{Referências}

Andreatta, V., \& Magalhaes, S. (2011). Relatório sobre as condiçoes do planejamento urbano, habitação e infraestruturas em Maputo. Moçambique: International Grawth Center.

Araújo, M. (1999). Cidade de Maputo espaços contrastantes: do urbano ao rural. Finisterra, 34(67-68), 175-190. https://doi.org/10.18055/Finis1694.

Araújo, M. (2001). Ruralidades-urbanidades em Moçambique. Conceito ou preconceito? Revista da Faculdade de Letras-Geografia, 1(16-18), 5-11. Recuperado em 10 de março de 2012, de http://ler.letras.up.pt/uploads/ficheiros/293.pdf

\footnotetext{
${ }^{23}$ Como mostrou um dos entrevistados (arquiteto Marcos, Maputo, 2013), o grande desafio que a urbanização moçambicana enfrenta é a inclusão de linhas orçamentárias.

${ }^{24}$ Essa parceria está acontecendo, mas de uma forma muito tímida, pois falta uma legislação que possa empoderar essa modelagem no processo da urbanização moçambicana (Nguenha, 2009).

${ }^{25}$ Nguenha (2009) apresenta como exemplo da parceria Estado-privado a construção da estrada N4, na cidade de Matola, cuja utilização é paga (portagem ou pedágio). Como se pode depreender, esse exercício constitui uma forma de o Estado transferir para o setor privado os riscos e os custos de projeção, construção e operação.
} 
Araújo, M. (2003). Os espaços urbanos em Moçambique. GEOUSP - Espaço e Tempo, 14, 165-182.

Associação Nacional dos Municípios de Moçambique - ANAMM. (2009). Desenvolvimento Municipal em Moçambique: lições da primeira década. Maputo: ANAMM.

Baia, A. (2004). Ruralidades na cidade de Nampula: exercício teórico por uma crítica da cidade (Dissertação de mestrado). Faculdade de Filosofia, Letras e Ciências Humanas da Universidade de São Paulo, São Paulo.

Baia, A. (2009). Os conteúdos da urbanização em Moçambique: considerações a partir da expansão da cidade de Nampula (Tese de doutorado). Faculdade de Filosofia, Letras e Ciências Humanas da Universidade de São Paulo, São Paulo.

Carrilho, J., \& Lage, L. (2009). Desafios no domínio da habitação. In L. Brito, C. N. Castel-Branco, S. Chichava, \& A. Francisco. Desafio para Moçambique 2010 (pp. 319-322). Maputo: IESE.

Carvalho, A. P. (2015). Acelerar o crescimento econômico e a criação de emprego, melhorar a educação e saúde para conquistar o dividendo demográfico em Moçambique. Maputo: Publifix Edições.

Castelo, C. (2007). Passagem para África: o povoamento de Angola e Moçambique com naturais de Metrópole (19201974). Porto: Edições Afrontamento.

Castelo, C., Thomaz, O., Nascimento, S., \& Cruz e Silva, T. (2012). Os outros da colonização: ensaio sobre o conialismo tardio. Lisboa: Imprensa de Ciências Sociais.

Cau, B., \& Arnaldo, C. (2015). Estimular a redução da fecundidade para conquistar o dividendo demográfico em Moçambique. Maputo: Publifix Edições.

Costa, A. B. (2011). Família de Maputo: processos de mobilidade e transformações urbanas. Revista Internacional em Língua Portuguesa, 3(23), 177-192.

Fanon, F. (2005). Os condenados da terra. Juiz de Fora: UFJF.

Folio, F. (2007). Les condominios à Maputo: enjeux sociétaux et spatiaux autour de l'implantation des ensembles résidentiels sécurisés dans la capitale mozambicaine. In Annales de Géographie 2007/3 (No. 655, pp. 247-270). http://dx.doi.org/10.3917/ag.655.0247.

Fonte, M. (2007). Urbanismo e arquitetura em Angola - Norton de Matos à revolução (Tese de doutorado). Faculdade de Arquitetura, Universidade Técnica de Lisboa, Lisboa.

Forjaz, J., Carrilho, J., Laje, L., Mazembe, A., Nhachungue, E., Battino, L., Costa, M., Cani, A., \& Trindade, C. (2006). Moçambique, melhoramento dos assentamentos informais, análise da situação \& proposta de estratégias de intervenção. Maputo: Direção Nacional de Planejamento e Ordenamento Territorial.

Hedges, D., \& Rocha, A. (1999). O reforço do colonialismo portugués, 1930-1937. In: Universidade Eduardo Mondlane. História de Moçambique: Moçambique no auge do colonialismo, 1930-1961 (pp. 35-83). Maputo: Universidade Eduardo Mondlane.

Ibraimo, M. (1994). Crescimento da população urbana e problema da urbanização da cidade de Maputo (Série População e Desenvolvimento, Documento, No. 11). Maputo: Unidade da População, Direção Nacional de Estatística.

Instituto Nacional de Estatística - INE. (2004). Inquérito nacional aos agregados familiares sobre orçamento familiar 2002/03. Quadros definitivos. Maputo: Instituto Nacional de Estatística.

Jenkis, P. (2001). Mercados de terras urbanas no Moçambique pós-socialismo. Seu impacto sobre a população vulnerável: alternativas para melhorar o acesso à terra e o processo de desenvolvimento urbano Projecto de pesquisaacção nas áreas peri-urbanas de Maputo. Maputo: Centro de Estudos de Desenvlovimento do Habitat da Universidade Eduardo Mondlane.

Mahumane, P. A. (2007). Somos uma identidade própria. Precorrendo as trilhas múltiplas identificações no contexto urbano do bairro Luís Cabral em Maputo (Dissertação de mestrado). Universidade Federal da Bahia, Salvador. 
Maloa, J. (2016). A urbanização moçambicana: uma proposta de interpretação (Tese de doutorado). Universidade de São Paulo, São Paulo.

Mapengo, M. (2011). Migração rural-urbana e crescimento populacional da cidade de Maputo. Maputo: Publifix, Lda.

Marchand, J. (1995). Économie et société dans la transition libérale au Mozambique. Paris: Karthala.

Mendes, M. C. (1979). Maputo: antes da independência: geografia de uma cidade colonial (Tese de doutorado). Universidade de Lisboa, Lisboa.

Mendes, R., \& Fernandes, M. (2012). Dicotomias urbanas em Moçambique: cidades de cimento e de caniço. Recuperado em 2 de janeiro de 2013, de sigarra.up.pt/flup/en/publs_pesquisa

Moçambique. Governo Geral da Colónia. (1942). Circular 818/D-7, 7 de outubro. Lourenço Marques: Governo Geral da Colónia de Moçambique.

Morais, J. (2001). Maputo, patrimônio da estrutura e forma urbana: tipologia do lugar. Lisboa: Livro Horizonte.

Moriconi-Ebrard, F., Harre, D., \& Heinrigs, P. (2015). L'urbanisation des pays de l'Afrique del'Ouest 1950-2010. Cahiers de l'Afrique de l'Ouest, Éditions OCDE. Paris: Africapolis I. http://dx.doi.org/10.1787/9789264252257-fr

Mosca, J. (2009). Pobreza, economia "informal”, informalidades e desenvolvimento. In Anais da II Conferência de Dinâmica da Pobreza e Padrões de Acumulação Econômica em Moçambique. Maputo: IESE. Recuperado em 2 de fevereiro de 2015, de http://www.iese.ac.mz/lib/publication/II_conf/CP34_2009_Mosca.pdf

Nguenha, E. (2009). Reflexões sobre processo público-privado no financiamento de Governos locais. Informação sobre Desenvolvimento, Instituições e Análise Social (No. 18, Boletim). Maputo: IESE.

Oppenheimer, J., \& Raposo, I. (2007). Entre os constrangimentos estruturais e a margem de manobra dos citadinos africanos: reflexões conceptuais e metodológicas. In J. Oppenheimer \& I. Raposo. Subúrbios de Luanda e Maputo (pp. 23-36, Coleção Tempo e Espaços Africanos). Lisboa: Colibri e Centro de Estudos sobre África e do Desenvolvimento.

Programa de Desenvolvimento das Nações Unidas - UNDP. (2007). National human development report 2006, Mozambique: acting now, planning for the future. The impact of HIV \& AIDS on human development. Maputo: Programa de Desenvolvimento das Nações Unidas.

Raposo, I. (2010). Explosão urbana em África: JANUS 2010 anuário de relações exteriores (pp. 184-185). Recuperado em 27 de outubro de 2017, de https://www.janusonline.pt/arquivo/popups2010/2010_3_5_3.pdf

Raposo, I., \& Salvador, C. (2007). Há diferença: ali é cidade, aqui é subúrbio: urbanidade dos bairros, tipos e estratégias de habitação em Luanda e Maputo. In O. Jochen \& I. Raposo. Subúrbios de Luanda e Maputo (Coleção Tempo e Espaços Africanos, pp. 105-138). Lisboa: Colibri e Centro de Estudos sobre África e do Desenvolvimento.

Serra, C. (2003). Em cima de uma lamina: um estudo sobre precaridade social em três cidades de Moçambique. Maputo: Imprensa Universitária, Universidade Eduardo Mondlane.

Silva, A. (2011). Dinâmica socioespacial e produção habitacional na periferia de Maputo-Moçambique a partir da década de 1970: destaque para bairros Polana Caniço " $A$ " E "B" (Dissertação de mestrado). Universidade Federal de Santa Catarina, Santa Catarina.

United Nations - Habitat - UN-HABITAT. (2007). Perfil do sector urbano em Moçambique. Nairob: UN-HABITAT.

United Nations - UN. (2007). World Population Prospects. The 2006 Revision (Vol. 1, Comprehensive Tables). USA: UN. Viana, D. (2010). Maputo: entre a cidade compacta, difusa e sem forma. IPEA, 7(63).

Viana, D. (2012). A urbanização extensiva [in] formal em Maputo a partir da retícula colonial. In Atas do Congresso Internacional Saber Tropical em Moçambique: História, Memória e Ciência. Lisboa: IICT-JBT-Jardim Botânico Tropical.

\section{Editor: Rodrigo Firmino}

Recebido: Jun. 08, 2018

Aprovado: Dez. 21, 2018 